\title{
PSICOLOGIA E RURALIDADE: REFLEXÕES PARA FORMAÇÃO EM PSICOLOGIA
}

\author{
Kátya de Brito e Silva \\ Universidade Federal do Piauí \\ João Paulo Macedo \\ Universidade Federal do Piauí
}

\begin{abstract}
Resumo
Os contextos rurais constituem um novo campo de atuação para as/os psicólogas/os. Porém, a relação entre Psicologia e rural ainda não se dá de forma estreita. O lugar das/os psicólogas/os nesse campo ainda está por se configurar. Diante dessa realidade, este ensaio desenvolvido por meio de uma pesquisa teórica visa debater mais amplamente sobre as possibilidades de inserção de rural na formação em Psicologia. Entende-se que o desafio é construir formações em Psicologia implicadas com a clareza das bases teóricas e práticas que norteiam o fazer técnico e ético no contexto das ruralidades, entendendo que a qualificação para esse campo não envolve apenas o campo técnico, mas o compromisso ético-político.
\end{abstract}

Palavras-chave: formação do psicólogo; ambientes rurais; interdisciplinaridade.

\section{PSYCHOLOGY AND RURALITY: REFLECTIONS FOR THE TRAINING IN PSYCHOLOGY}

\begin{abstract}
Rural contexts are a new field of practice for psychologists. However, the relationship between psychology and the rural still is not close enough. Psychologists' place in this context, therefore, is still configuring itself. Considering this reality, this essay, developed through a theoretical research, aims to discuss broadly the possibilities of incorporation of the rural in Psychology courses. It is understood that the challenge is to develop training in psychology that is dedicated to clarify theoretical and practical bases that can guide techniques and ethical issues of the rural context, understanding that the qualification in this field does not involve only technical aspects but also ethical-political commitment.
\end{abstract}

Keywords: psychologist training; rural environments; interdisciplinarity.

\section{PSICOLOGÍA Y RURALIDAD: REFLEXIONES PARA FORMACIÓN EN PSICOLOGÍA}

\begin{abstract}
Resumen
Los contextos rurales constituyen un nuevo campo de actuación para las/los psicólogas/os. Sin embargo, la relación entre Psicología y rural aún no se configura de forma estrecha. El lugar de las (los) psicólogas (os) en ese campo, por lo tanto, aún está por configurarse. Ante esta realidad, este ensayo es desarrollado por medio de una investigación teórica objetiva debatir más ampliamente sobre las posibilidades de inserción del rural en la formación en Psicología. Se entiende que el desafío es construir formaciones en Psicología implicadas con la claridad de las bases teóricas y prácticas que orientan el hacer técnico y ético en el contexto de las ruralidades, entendiendo que la calificación para ese campo no implica sólo el campo técnico, sino el compromiso ético -político.
\end{abstract}

Palabras clave: formación del psicólogo; ambientes rurales; interdisciplinariedad. 


\section{INTRODUÇÃO}

Entendido como uma categoria do pensamento teórico, mas também do senso comum e de classificação da vida social (Moraes, 2014), rural diz respeito a uma representação e não uma realidade empiricamente observável (Carneiro, 1998). Conectado e inseparável do urbano e, paralelamente, menos associado a atividades agrícolas (Silva, 2001), rural só pode ser pensado em termos de "novas e múltiplas faces" (Wanderley, 2000, p. 134), tendo sido bastante comum nas ciências sociais a utilização das expressões ruralidade, ruralidades e ruralidades contemporâneas para referir-se a esse tema.

Ressalta-se que esse modo de conceber rural faz parte de um processo de ampliação de sentidos. Comumente, rural foi associado a um local físico, atrasado, tradicional, resistente a mudanças (Moreira, 2005a), periférico (Do Carmo, 2009), sinônimo de pobreza (Matos \& Medeiros, 2011), enquanto o urbano foi representado como o oposto: polo mais avançado e moderno, portanto, o centro da sociedade (Do Carmo, 2009; Matos \& Medeiros, 2011). Tal dicotomia, na verdade, é reflexo de outra: campo versus cidade. Trata-se de uma oposição que foi gestada pela sociedade capitalista, que acentuou a divisão do trabalho e enraizou determinada maneira de representar e classificar o mundo nessas duas realidades (Williams, 2011). Para Moreira (2005a), além dos aspectos econômicos expressos na dicotomia rural-urbano, tal relação ainda é atravessada pelos poderes assimétricos das sociedades capitalistas que influenciam as esferas políticas e culturais existentes, constituindo-se como polos construtores de identidades donde emergem atribuições de sentido de um e outro.

Outra perspectiva que tem empreendido sentidos a rural é a do continnum rural-urbano, em que ambos são entendidos como um gradiente de variações espaciais, de maneira que se vai de uma situação (rural) a outra (urbano), constituindo relações de contato e gradação, espécie de continuidade entre os dois espaços, porém, resguardadas as particularidades que os define (Lindner, Alvez, \& Ferreira, 2009). Para alguns autores a proposta do continnum se apresenta em contraposição ao enfoque dicotômico; para outros trata-se apenas de uma variação analítica do mesmo, pois acabam priorizando um processo gradual de urbanização do campo (Candiotto \& Corrêa, 2008; Camargo \& Oliveira, 2012). Nesses termos, a principal crítica à noção de continuum é que este privilegia urbano como detentor do progresso e dos valores dominantes, enquanto o rural, o outro extremo, permanece caracterizado como atrasado, tendendo a reduzir-se sob a forte influência do anterior (Wanderley, 2000).

A partir de meados de 1970, dentre outras abordagens que surgiram nessa época, rural passou a ser abordado na perspectiva da sociologia da agricultura. O debate sobre rural dá lugar aos estudos sobre agricultura (Blume, 2004). Fala-se de uma nova abordagem teórico-metodológica, que tem como 
objeto o estudo das relações sociais que ocorrem na agricultura, definida, sobretudo, pelo pensamento contrário e de negação aos pressupostos da rural sociology. No Brasil, a discussão dessa abordagem deu-se no final de 1980, por meio de estudiosas/os da agricultura e da questão agrária (Cavalcanti, 2004; Schneider, 1997).

Somente nos anos 1990 é que os estudos rurais ganham nova força no Brasil (Wanderley, 2011). Data dessa época algumas mudanças nas análises sociológicas sobre rural brasileiro (Brumer \& Santos, 2000), sendo a principal o deslocamento do foco da agricultura e da dicotomia rural/urbano (Silva, 1982; 1987) para o diálogo com novas bases conceituais, expressas principalmente por meio do debate da sociologia, antropologia, agronomia, geografia e economia. Autores como Silva $(1980 ; 1982 ; 1996)$ passaram a defender a existência de um novo rural brasileiro. Wanderley $(2000 ; 2001)$ aponta em seus estudos sobre rural como lugar de vida e trabalho. Carneiro (1998; 2008; 2012) e Moreira (2002; 2009; 2010) colocam em evidência a subversão do rural às pressões do meio urbano. E, mais recentemente, autores como Veiga (2001) sugerem uma nova leitura sobre rural a partir do enfoque territorial.

Esse rápido panorama nos convoca a pensar a respeito da amplitude que o debate sobre rural ganhou na atualidade. Sendo necessário compreender rural como uma categoria teórica a qual possui diferentes perspectivas, e que precisam ser reconhecidas, acima de tudo, a partir das capacidades e limites heurísticos que comportam. Nesse sentido, o debate em questão não estaria centrado na redefinição das fronteiras do rural e do urbano, mas em "orientar nossos esforços para buscarmos, a partir do olhar dos atores sociais, os significados das práticas sociais que tornam operacional esse tipo de interação (e distinção)" (Carneiro, 2012, p. 45).

Tais balizadores ajudam a situar o uso da expressão ruralidade, comumente utilizada nos estudos sobre esse campo, referida à extensão de significados culturais atribuídos a rural no contexto do estreitamento de suas relações com o urbano e, nesse sentido, pensada na relação e não pela oposição com a cidade (Calegare, 2015). Daí a compreensão de que "ruralidade dentro dessa perspectiva está em constante construção e deve ser percebida através da interação entre os atores sociais e os sistemas culturais aos quais eles estão referidos" (Carneiro, 2012, p. 19). Mas, por outro lado, é importante esclarecer que as interações espaciais dicotômicas entre rural e urbano não foram superadas e que apesar das novas linhas de interpretação, a discussão proposta pelos estudos clássicos não pode ser desconsiderada.

No caso brasileiro, toda essa discussão ganha maior relevo em função da imensa diversidade sociocultural e fundiária do país (Little, 2002), com novas configurações e identidades socioespaciais se (re)construindo, de forma que "o velho' e o 'novo', o antigo (a 'tradição') e o 'moderno', compõem-se, justapõemse, ou mesmo se fundem peculiarmente" (Froehlich, 2012, p.222). As 
identidades estão, nesse contexto, em constante (re)elaboração e tendem a ser "fluidas, híbridas e multirreferenciadas", movimento que explica o porquê de indivíduos e grupos sociais envolverem-se de maneira frequente com "situações paradoxais e ambíguas, muitas vezes assumindo condições e comportamentos ambivalentes" (Froehlich, 2012, p.222).

Nesse universo de variações e conexões, vale destacar que a agricultura tem se tornado apenas uma dentre as várias atividades exercidas por membros de famílias rurais e suas dimensões não produtivas têm contribuído para a continuidade da vida social local tão quanto às produtivas. Ou seja, têm sido utilizadas variadas estratégias que combinam agricultura com outras atividades não agrícolas às quais possibilitam a permanência das famílias em suas localidades de origem. Isso demanda a necessidade de novas análises que visem à formulação de políticas públicas para essas populações que considerem as condições multifuncionais do território, de maneira que o foco central seria deslocado da agricultura para outras atividades produtivas, que juntas são articuladas pelas populações para manter o "tecido social local" (Carneiro \& Teixeira, 2012, p.93).

Todas essas diversidades e dinâmicas produzem uma série de questões que se processam nas diferentes situações em que as ruralidades são vivenciadas no Brasil contemporâneo, cujas respostas demandam ultrapassar os limites de uma espacialidade física (Carneiro, 2005), pois não respondem à dinâmica de sociabilidades mais complexas; ao tensionamento de identidades sociais em disputa; aos valores rurais e urbanos justapostos, e às disputas e assimetrias culturais e políticas envolvidas.

Nesse sentido, ao olhar para a realidade agrária do Brasil é possível verificar, de acordo com Fernandes, Welch e Gonçalves (2013), que é constituída por paradoxos. De um lado, estão os grandes avanços na agricultura, do outro, a manutenção do trabalho escravo contemporâneo, o aprofundamento da fome e da pobreza, a não realização do projeto de reforma agrária e a ampliação dos conflitos por terra. A questão agrária permanece sem solução e os povos rurais têm sido destituídos de suas terras e modos tradicionais de vida, enfim, cada vez mais marginalizados.

Tais apontamentos abriram novas compreensões para o tema, pois mais recentemente os contextos rurais passaram a representar um novo e importante campo de problematização e atuação para as/os psicólogas/os, especialmente por meio de sua integração às equipes de atenção básica da saúde e de proteção social básica da assistência social, não esquecendo as experiências relacionadas à extensão rural e à educação no campo (Landini, 2015; Leite, Macedo, Dimenstein, \& Dantas, 2013). Porém, diferentemente de outras áreas do conhecimento, a Psicologia não possui uma trajetória consolidada no debate sobre rural, sendo considerado um campo de discussão recente (Leite et al., 2013). 
Calegare (2015), inclusive, alerta quanto à ausência de aprofundamento com a variação de termos nos estudos que têm tratado sobre o tema: "ambiente rural, meio rural, contexto rural, zona rural, área rural, etc." (p. 439). Ressalta o autor que não se trata de uma simples questão semântica, pois cada um dos "termos" refere a diferentes concepções e visões de mundo sobre rural. Além disso, rural não pode ser tomado somente como simples lócus de atuação para profissão; mais do que um local, unidade geográfica, trata-se de uma categoria que precisa ser tomada em seu significado socioantropológico. Isso inclui reconhecer os processos psicossociais dinamizados nos diferentes contextos e faces em que o rural é representado na contemporaneidade.

Nesses termos recupera-se o debate francês sobre rural, proposto por Kayser (1990), que compreende rural como um determinado espaço físico (alusão à ocupação do território e aos seus símbolos), mas também como lugar onde se vive (particularidades do modo de vida) e de onde se vê e se vive o mundo (cidadania e inserção de sujeitos rurais nas amplas esferas da sociedade). Para Wanderley (2000), recuperar esta tradição possibilita compreender os contornos, as especificidades e as representações do rural na heterogeneidade que o termo comporta: ora representado pela atividade agrícola familiar; ora pela agropecuária moderna, intimamente ligadas às agroindústrias; ora pela pluriatividade, pelas questões ecológicas e pelo desenvolvimento do lazer e do turismo; mas também pela prestação de serviço e das chamadas "novas" atividades agropecuárias com nichos especiais de mercados; e pela marca das/os novas/os agricultoras/es de origem urbana que têm cada vez mais deslocado a clássica representação sobre rural; dentre outros. Esse conjunto de situações tem impactado em mudanças na composição populacional de diversas e variadas localidades rurais no país, tendo surgido outras formas de conceber e dar significado aos espaços e experiências rurais. É nesse bojo que Moreira (2005b) refere-se à ruralidade como expressão de identidades sociais engendradas a partir das disputas sociais e políticas que ocorrem no território.

Partindo dessas formulações, coloca-se a questão de como pensar a inserção sobre rural no debate sobre a formação em Psicologia, considerando que a profissão tem avançado em direção a realidades das populações e dos contextos rurais, mas que, contraditoriamente, ainda baliza o seu olhar sob o crivo das representações dos contextos urbanos (Albuquerque, 2001, 2002; Leite et al. 2013).

Para abordar o tema, o presente ensaio está organizado da seguinte forma: a) Rural e as demandas para formação em Psicologia; b) Formação em Psicologia para o trabalho com ruralidades: conexões e possibilidades; c) Psicologia Comunitária/Psicologia Social Crítica: possibilidades de atuação em contextos rurais? 
O material apresentado é fruto de um estudo teórico junto a diferentes áreas do conhecimento e de produções já existentes no âmbito da Psicologia a respeito de rural.

\section{I -RURAL E AS DEMANDAS PARA FORMAÇÃO EM PSICOLOGIA}

Apesar dos contextos rurais constituírem na contemporaneidade um importante campo de atuação profissional para Psicologia, além de se ter registrado certo aumento de pesquisadoras/es indagando e refletindo sobre as possíveis contribuições a respeito de rural (Albuquerque, 2001, 2002; Calegare, 2015; Domingues, 2007; Leite \& Dimenstein, 2006, 2010; Lemos \& Galindo, 2013; Lopes, 2007; Rosa \& Silva, 2015; Vasquez, 2009), os estudos que tratam sobre o tema da formação voltada para esse campo são escassos (Leite et al. 2013; Martins, 2010; Vasquez, 2009).

Tal realidade reflete a insuficiência do debate histórico realizado nas graduações em Psicologia no Brasil, em que temas ligados à formação social brasileira são muito pouco explorados. Debates sobre a "questão social", por exemplo, enquanto expressão de um conjunto multifacetado de desigualdades econômicas, políticas e culturais, engendradas na sociedade capitalista, em sua fase monopolista, cujo resultado é a marginalização de amplas parcelas da sociedade em relação aos bens materiais e simbólicos produzidos pela civilização (Ceolin, 2014), encontra pouca ressonância na formação e exercício profissional da/o psicóloga/o brasileira/o brasileira/o. Diante desse quadro, Guzzo (2015, p. 05-06) é taxativa quando refere que "[...] nada mudou na formação que pudesse fornecer aos estudantes oportunidades de refletir criticamente sobre as distintas faces da "questão social" e como a Psicologia deve se organizar diante delas".

O afastamento da Psicologia em relação à "questão social" reflete a maneira como a profissão surgiu no Brasil, não direcionada a compreender as relações de poder, dinâmicas e antagonismos que permeiam a vida social. A ausência de um debate mais aprofundado sobre as condições e o contexto de inserção da Psicologia na divisão social e técnica do trabalho da sociedade capitalista, e sua localização e funcionalidade na sociedade burguesa, com a prestação de serviços atendendo aos interesses da regulação social (individualização dos problemas sociais e adaptação e ajustamento do comportamento), é o que tem, em suma, legitimado e garantido, em certa medida, a imagem social da profissão. O não enfrentamento desse debate abre uma lacuna ainda maior que é a pouca compreensão do caráter universal e mundializado da "questão social" que comporta ainda particularidades culturais, geo-políticas e nacionais, com diferenças e particularidades histórico-culturais que se cruzam e tencionam em cada realidade (Netto, 2001). A realidade dos contextos e dos povos rurais certamente não está isenta dessas determinações. 
Acentua-se que na realidade do Brasil, a "questão social" tem intima relação com a questão agrária e as questões relativas à terra e às ruralidades em geral. Dessa forma, existem contextos rurais atravessados por expressões da "questão social" como contradições sociais, desigualdade, miséria, pobreza, fome; e pelos diferentes, e muitas vezes, contraditórios interesses das políticas, dos serviços e das populações. Tal quadro coloca muitos desafios à formação em Psicologia, que como referido alhures, manteve-se por muito tempo distante do debate sobre rural e sobre a questão social.

Apesar disso, acredita-se que a Psicologia pode instituir ações inovadoras e, com isso, "... extrapolar o viés individualista e normatizador que, por décadas, hegemonicamente, embasaram o trato às expressões da questão social" (Leão, Oliveira \& Carvalho, 2014, p. 284). Cabe questionar: quais são as já conhecidas e novas expressões da "questão social" que vêm se desvelando nos contextos rurais? Como os elementos saúde, educação, trabalho, desenvolvimento, cidadania, justiça social, vulnerabilidade, entre outros, vêm se expressando nos contextos rurais e como podem ser trabalhados pelas/os psicólogas/os? Tornase, portanto, imprescindível inserir a discussão sobre "questão social" na formação em Psicologia, para que somada a outras interpretações, contribua para a análise e intervenção com rural.

De fato, como verificado por Bernardes (2012) em investigação sobre a formação em Psicologia, os sentidos produzidos em considerável parte dos cursos do Brasil reproduzem o que já existe por meio de ênfases curriculares centradas nos domínios mais consolidados de atuação que é a Psicologia Clínica, a Psicologia Escolar e a Psicologia Organizacional. Isso se expressa nas pesquisas sobre a formação de psicólogas/os no Brasil identificadas por Costa et al. (2012) ao verificarem que parcela importante tem focalizado as discussões nessas áreas tradicionais e, além disso, podem ser caracterizadas como uma produção dispersa, com caráter opinativo e em grande medida, focada em uma ótica internalista para abordar o tema. A partir disso, as/os autoras/es questionam: "será que as áreas consagradas são suficientes para se pensar a preparação desse profissional?" (Costa et al., 2012, p. 136). E mesmo sem prescindir desses conhecimentos, é possível "refunda-los" na perspectiva de atender as especificidades das necessidades em saúde, de trabalho e do processo de escolarização que demandam os povos e os meios rurais no Brasil?

Trazendo essas perguntas para o contexto atual, compreende-se a importância do debate sobre rural como meio de contribuir para a reflexão da própria direção e compromisso ético-político da formação em Psicologia com a sociedade brasileira, pois requisita aproximação com novas faces da questão social, dinâmicas, compromissos e lutas. Por isso, cabe superar as lacunas da formação acadêmica voltada para rural, pois são elas que parecem explicar a negligência científica da Psicologia em relação a populações rurais (Martins, 2010). 
Por outro lado, mesmo com todas as carências teórico-práticas, a Psicologia Social vem se colocando como campo promissor de pesquisas e intervenções nessa área. Ela é mencionada no estudo de Landini (2015) quando fez referência à obra "Our rural heritage. The social psychologyof rural development" (Nossa herança rural: a psicologia social do desenvolvimento rural), publicada por James Williams, em 1925, nos EUA, considerada um marco nos estudos nesse campo. No Brasil, em 1960 e 1970, há registros de trabalhos de psicólogas/os, no âmbito da Psicologia Social Comunitária, na região Sudeste e Nordeste do país. A partir daí, seguiu certo volume de trabalhos também vinculados ao âmbito da Psicologia Social, divulgados em congressos e em periódicos científicos nacionais e internacionais, ainda que de forma dispersa. Mais recentemente, em 2013, o documento: "Referências Técnicas para Atuação das/os Psicólogas/os em Questões Relativas à Terra", elaborado pelo Centro de Referências Técnicas em Psicologia e Políticas Públicas (CREPOP), propôs a Psicologia Social como o grande campo de referências na produção de pesquisas e intervenções nas questões relativa à terra, bem como os seus desdobramentos sob a perspectiva das chamadas "Psicologias Críticas" (Psicologia Sócio Histórica, Psicologia Comunitária, Psicologia Política, Psicologia Institucional, e em articulação com os Movimentos Sociais, etc.), porque possibilitam compreender a complexidade dessas realidades.

Essa complexidade de questões que envolve o campo das ruralidades diz respeito ao conjunto de mudanças decorrente do estreitamento das fronteiras entre rural e urbano no país, mas também frente à ampliação e os rumos do debate sobre os estudos rurais no Brasil. Conforme referimos antes, trata-se de um campo marcado por ambiguidades e disputas entre diferentes posturas teóricas, diferentes paradigmas e seus quadros de linguagens, categorias e temas, além de ser atravessado por novas questões de conteúdo metodológico (Almeida, 2007; Carneiro, 2005).

É nesse contexto que outras questões surgem: que meios e estratégias a Psicologia pode utilizar para lidar e contribuir com os desafios que perpassam o próprio campo dos estudos rurais? Como qualificar a formação em Psicologia para manejar as singularidades, complexidades, diversidade de sentidos e de atores, além de compreender a relação com o urbano e transformações envolvidas nos contextos rurais?

Tais questionamentos ajudam a reafirmar a escassez de preparo teórico, técnico e metodológico da Psicologia em relação às diversidades e especificidades dos contextos e povos rurais, ao mesmo tempo em que sinalizam para o risco de ficar preso a demanda por ações mais imediatistas tão comuns nos serviços das políticas sociais. Esse é um ponto que precisa ser encarado como uma preocupação central a ser superada. É preciso entender, de acordo com Coelho (2013), que quanto mais pobre for a concepção acerca da teoria e o conhecimento que se tem dela, mais imediatista será a prática profissional. Para 
Montaño e Duriguetto (2010), respostas imediatas e diretas que não consideram as mediações entre necessidade, pensamento e ação, reverberam em intervenções alienadas, repetitivas e ingênuas.

Por esse aspecto, a ideia não é fragmentar rural como uma especialidade com um saber-fazer específico e reduzido a uma teoria. Landini (2015), na Argentina, tem utilizado em suas publicações o termo Psicologia Rural, tendência também acompanhada, em menor peso, em outros países da América Latina. No Brasil, não há um consenso de como nomear os estudos nesse campo, visto que, seguir a lógica de adjetivar a Psicologia semelhante ao que ocorre em outras subáreas (clínica, escolar, comunitária, jurídica, etc.), em que rural, no caso, passaria a ser o "local" em que são investigados certos fenômenos psicológicos, não responde, na opinião de pesquisadoras/es da área, à heterogeneidade e a complexidade de discussões sobre rural no Brasil. Desta forma, autoras/es brasileiras/os têm preferido utilizar as expressões "psicologia em contextos rurais" ou "psicologia nos cenários rurais", ou, ainda, simplesmente em áreas rurais ou meio rural. Assim, o interesse é, por outro lado, contribuir com uma formação atenta às necessidades dos povos rurais e voltada para transformação e emancipação humana, superando o imediatismo na prática profissional, por meio da construção de norteadores teóricos e técnicos mais robustos e éticopoliticamente posicionados.

Deste modo, torna-se necessário a redefinição da formação profissional e, esse processo requer, sem dúvida, o avanço para além da redefinição dos currículos, incluindo o aumento da produção do conhecimento sobre o tema, o aprofundamento do debate acerca das alternativas de capacitação continuada, a participação das entidades representativas da categoria nessa discussão, além da aproximação dos movimentos sociais do campo, por meio de projetos e ações de extensão universitária. Tendo em vista que hoje não se trata mais de escolher trabalhar em um "local" urbano ou rural, pois por suas relações tênues (Carneiro, 2005) e o fato de que rural é um objeto multifacetário e requer olhares polivalentes (Wanderley, 2012), estando, portanto, em constante construção (Carneiro, 2012), a Psicologia e as/os psicólogas/os são interpeladas/os por rural e vivenciam as relações rural/urbano cotidianamente. Por este aspecto, cabe à formação profissional em Psicologia acompanhar esse movimento, por meio de uma preparação coerente e específica às distintas realidades dos contextos e povos rurais no Brasil.

\section{II - FORMAÇÃO EM PSICOLOGIA PARA O TRABALHO COM RURALIDADES: CONEXÕES E POSSIBILIDADES}

De acordo com Carneiro (2005), em se tratando dos contextos rurais, para que se possa responder aos impasses que a complexidade dessas realidades tem atribuído à teoria, torna-se necessário um olhar histórico sobre a produção do 
conhecimento a respeito de rural. Essa afirmação, somada às questões já levantadas neste ensaio, sem dúvida, contribui para sustentar a posição de que a formação profissional voltada para contextos rurais precisa ser priorizada. Afinal, como a Psicologia pode lidar com as complexidades impostas à profissão, quando minimamente não conhece o campo dos estudos rurais?

Cabe repensar o ensino e a prática orientados pela experimentação e construção de uma Psicologia inseparável da política e da vida, a partir de processos de reformas curriculares e práticas vivenciadas por dentro e por fora dos componentes curriculares, em articulação com ações de pesquisa e extensão universitária. É preciso atentar para que não ocorra a minimização do debate apenas no incremento de conteúdos e disciplinas relativas ao universo das ruralidades, pois parte-se do entendimento de que o currículo é permeado por relações, poderes e produção de subjetividade. Nesse sentido, é fundamental que contemple além das questões deontológicas, epistemológicas e metodológicas, o diálogo, o encontro e a alteridade, pois o "currículo é vida, e, portanto, é desejável que esteja na pele das pessoas, encarnado em seus corpos, vivenciado e em constante processo de avaliação e mutação" (Bernardes, 2012, p. 220).

Algumas conexões e proposições são importantes na tentativa de tracejar respostas a algumas das indagações realizadas anteriormente a respeito da formação em Psicologia para a atuação em contextos rurais. Nesse sentido, são temas relevantes para a formação, mas também para pesquisas em Psicologia nesse campo:

a) História do campo brasileiro e de suas populações regionais; b) História das lutas indígenas e camponesas no Brasil e na América Latina; c) A emergência atual dos povos do campo no Brasil e na América Latina; d) Políticas públicas atuais e o campo brasileiro; e) Estado e hegemonia cultural; f) Políticas públicas, subjetividades e culturas; g) Estado, políticas culturais e práticas culturais; h) Sociedade, relações de classe e relações étnicas; i) Antropologia Cultural; Etnologia e Etnografia; j) Ciências da Religião; k) Povos Indígenas no Brasil; Comunidades Tradicionais no Brasil e, I) Formação e atualidade dos quilombos no Brasil (CREPOP, 2013).

Além disso, considera-se importante inserir nos currículos de Psicologia conteúdos a respeito das lutas sociais e a questão da terra; questão agrária; contradições do modelo produtivista de modernização da agricultura; processos sociais, culturais e identitários; reconstrução do espaço rural; infância, adolescência, juventude e velhice em contextos rurais; relações de gênero e de gerações em contextos rurais; sexualidades; violências; famílias rurais; desenvolvimento rural sustentável; processos de assistência técnica e de extensão rural, dentre outras, no intuito de avançar no saber-fazer da Psicologia em relação a esse campo. 
Porém, é importante salientar que não basta a inclusão desses temas. É necessário que as universidades realizem diálogos e construam parcerias com organizações representativas de povos indígenas, quilombolas, comunidades tradicionais, camponesas, dentre outras, no sentido de que possam contribuir no acesso de professoras/es, alunas/os e pesquisadoras/es à realidade do campo com o seu universo social e étnico-cultural, como também podem contribuir com a aproximação dos povos rurais na vida acadêmica (CREPOP, 2013).

Assim, a aproximação da Psicologia com os contextos rurais suscita uma série de questões à formação, que perpassam desde a formação acadêmica adequada para a atuação nesse campo e as delimitações do papel da/o profissional até a formação de um corpo qualificado de conhecimento teórico e técnico que norteie a intervenção. Por se tratar de um campo que demanda uma multiplicidade de conhecimentos, já que como foi possível perceber, lida com uma variedade de sujeitos, contextos, questões, teorias e disciplinas, exige da formação uma qualificação adequada no sentido de acompanhar toda essa diversidade e complexidade.

Nesse sentido, cabe à formação ser pensada como espaço a ser estudado e construído, no sentido de contemplar rural não apenas de maneira acessória, mas fundante nos currículos, contribuindo para a clareza das bases teóricas e práticas que norteiam o fazer técnico e ético no contexto das ruralidades. Tornase necessária a aproximação com áreas que já possuem uma trajetória nesse campo, como a Sociologia, Antropologia, Economia, e Geografia, como forma de situar-se frente aos avanços já realizados e às questões que têm sido levantadas.

Porém, não basta apenas incrementar os currículos com temas e discussões de outras áreas do conhecimento. Cabe refletir acerca de uma formação teórico-crítica e prático-operativa. Nesse sentido, é válido destacar que a formação em Psicologia precisa firmar-se como espaço que não apenas produz técnicas/os, mas sujeitos atentos às implicações políticas de suas práticas profissionais. A qualificação para atuação de psicólogas/os em contextos rurais não envolve, nesse sentido, apenas o campo do conhecimento profissional e a qualificação técnica voltada para rural, mas o compromisso ético-político, o que requer uma "competência técnica e ético-política que subordine o "como fazer" ao "o que fazer" e, esse, ao "dever ser", sem perder de vista seu enraizamento no processo social" (Iamamoto, 2008, p. 80).

Não há como negar: a formação está intimamente ligada ao projeto de profissão (Rechtman, 2015), e por isso, cabe questionar, em meio aos diferentes projetos de Psicologia para a realidade brasileira, a qual se está filiado/a. Qual projeto se quer construir? Qual o lugar das ruralidades e dos povos rurais nesse projeto?

Portanto, cabe refletir acerca uma formação atenta aos desafios da atual conjuntura brasileira, marcada, por exemplo, pelo avanço do conservadorismo; 
criminalização da pobreza e dos movimentos sociais; desrespeito aos direitos humanos; ameaças à liberdade de expressão e pensamento; retrocesso das políticas públicas frente a interesses do mercado; super-responsabilização dos indivíduos pela sua própria proteção; precarização do trabalho e das condições éticas e técnicas para o exercício profissional (Cardoso, 2013); ênfase na área econômica, na modernização e no agronegócio.

\section{III - PSICOLOGIA COMUNITÁRIA/ PSICOLOGIA SOCIAL CRÍTICA: POSSIBILIDADES DE ATUAÇÃO EM CONTEXTOS RURAIS?}

Como já dito, apesar das insuficiências e lacunas teóricas e práticas da Psicologia em relação a rural, a produção científica da Psicologia Social Brasileira tem aglutinado perspectivas mais críticas que têm se debruçado sobre temas que estão na ordem dos debates pautados pelos estudos rurais. Nesse sentido, destacaremos a Psicologia Comunitária por trabalhar com determinados objetos e dinâmicas que têm historicamente relação direta com os contextos rurais.

Trata-se, aqui, de conceber a Psicologia Comunitária como uma área do conhecimento e um campo de atuação profissional importante para o desenvolvimento de uma nova conformação da Psicologia "sobretudo, para o combate e subalternidade dos povos latino-americanos", colocando-se como uma opção para um espaço de intervenção comprometida, principalmente, com as questões sociais (Guzzo, 2016, p. 146).

É importante lembrar que, no geral, a Psicologia Comunitária é constituída pela Psicologia Comunitária Norte-Americana e a Psicologia Comunitária LatinoAmericana (Sawaia, 2007). Esta última ganha destaque com as contribuições da "Escola de São Paulo" de Psicologia Social acerca da compreensão do psiquismo, da consciência humana e da proposição de práticas psicossociais (Lane \& Sawaia, 1995; Martins, 2007). Dentre as várias categorias utilizadas por Lane (2007), sobressai-se a consciência e a atividade, fundamentais na compreensão do psiquismo humano, pois sistematizam comportamento, aprendizagem, cognição, identidade e afetividade, especialmente quando se busca resgatar a subjetividade, levando ao conhecimento de aspectos singulares mediados pelas condições concretas de vida e de trabalho que conformam os indivíduos e os grupos sociais a que pertencem.

Neste trabalho, tomamos a ideia de território como central na empreitada para discutir a relação da Psicologia Comunitária com contextos rurais. Isso se deve ao fato de considerarmos a natureza territorial envolvida no conceito de ruralidade (Abramovay, 2000). Para Favareto (2006) existe uma forte ideia de espacialidade relacionada à rural que desafia a sua compreensão em termos territoriais, apesar de se observar - e isso não diz respeito apenas à Psicologia que na formulação das políticas públicas, assim como na mobilização de 
determinados atores sociais, ainda existe uma forte orientação pela abordagem setorial.

Partimos do entendimento de território como imagem, representação, que é alimentada e ao mesmo tempo alimenta uma rede de relações sociais (Carneiro, 2012); "lugar de memória e de referência para a construção da identidade social" (Wanderley, 2011, p. 123). Para Dimenstein et al. (2017), o território é um

[...] campo de forças heterogêneas, delimitação espacial das relações de poder, das desigualdades, no qual o substrato físico torna-se um elemento mediador ou mesmo condicionante. Configura-se, pois, como uma trama complexa entre processos sociais e espaço material, escapando à superação da dicotomia social-espacial, uma vez que o território é componente indissociável dos processos sociais e não apenas um terreno em que estes se desenvolvem (p. 76).

No caso das ruralidades, entendidas como expressões de identidades sociais no mundo rural, entende-se a noção de identidade territorial que passa por um processo de ressignificação de uma noção de território herdada da modernidade para uma nova noção associada à natureza e aos processos de produção e reprodução da vida; as disputas territoriais expressam diversos e diferentes interesses, como rurais e urbanos e locais/nacionais/globais, entre outros; o território expressa disputas sociais e políticas nas quais são construídas identidades sociais. Nesse sentido, há um jogo de interesses e disputas, demonstrando que o território é um espaço de exercício da política e envolve a expressão de poderes assimétricos (Moreira, 2005b).

Essas noções de território ao ampliarem o seu entendimento para além das questões físicas e materiais incluindo as simbólicas e relacionais, contribuem para reafirmar o sentido de ruralidade como representação (Carneiro, 2008) e sua relação existente com o urbano. Nos termos de Favareto et al. (2015), existe entre os espaços rural e urbano uma "conectividade física e virtual", na conformação de uma "trama territorial" (p. 21). Desse modo, os conceitos de território e ruralidade se aproximam compreendidos para além do aspecto físico, pois comportam uma complexidade que inclui várias dimensões não-materiais e suas diferentes combinações. Por esse aspecto, abre-se diversas possibilidades para psicólogas/os ampliarem as formas de compreensão sobre os processos psicossociais e comunitários envolvidos nos diferentes contextos rurais em que atuam.

Assim, a perspectiva territorial implica em "considerar as múltiplas determinações e singularidades dos modos de vida, das relações afetivas, das sociabilidades e vínculos entre sujeitos e instituições", com ações pautadas em um diagnóstico e planejamento situacional voltado para as formas como as populações se relacionam nos espaços onde vivem e desenvolvem suas atividades habituais e que valorizem a diversidade espacial, social e simbólica que está presente nos diferentes cenários (Dimenstein et al. 2017, p. 73-74). 
Não poderíamos deixar de destacar uma importante noção que vem sendo utilizada nas Ciências Sociais, como auxílio à Psicologia Comunitária na sua aproximação com rural em termos territoriais, a noção de localidade. Esta, não denota apenas uma experiência espacial,

não se traduz simplesmente por um espaço fisicamente delimitado e socialmente ocupado. Ela seria útil justamente porque supõe um espaço que é tido por aqueles que ocupam como uma referência e como uma base física de um conjunto de relações sociais diversificadas (de trocas, de sociabilidade, de solidariedade, de disputas, de conflitos) que dão sentido à existência de seus habitantes, isto é, Ihe dão uma referencia identitária (Carneiro, 2012, p.49).

Desse modo, o vínculo entre a categoria território e a Psicologia Social Comunitária é justificado pelo destaque ao uso conceitual do território como categoria psicossocial e relacional (Conti, 2016). Assim, um importante objeto de estudo da Psicologia Social que pode contribuir para análises a respeito de rural, trata daquilo que ficou conhecido na literatura em Psicologia como sofrimento ou mal-estar psicossocial, produzido a partir das condições de existência; responsável por corroer o sistema de resistência social e romper, por meio da supressão da emoção e da anulação do pensar na atividade, o nexo entre pensar, sentir e agir. Nesse processo, a consciência é entendida não apenas na forma de conhecimento explicativo, mas no aspecto intuitivo-emocional que traduz ou expressa certa visão de mundo e acaba facilitando espaços para inclusão dos desejos, necessidades e emoções no processo de conscientização.

A prevenção, portanto, do sofrimento psicossocial dá-se em um lugar considerado privilegiado, que é o local da vida cotidiana. A intenção é transformar esse lugar em ponto de "segurança, afetividade e de tolerância à pluralidade de formas de viver" (Sawaia, 1995, p. 52), sem perder o sentido e vínculo às lutas sociais do campo e em torno da questão da terra. Daí a importância de voltar-se para a comunidade, seja espaço geográfico ou território psicossocial, pois é onde grande parte da vida cotidiana é vivida (Campos, 2015).

A vida cotidiana com toda sua complexidade, contraditoriedade e ambiguidade, que "se insere na história, se modifica e modifica as relações sociais", que reflete "a vida de todos os dias e de todos os homens", e que afirma "um espaço de resistência e possibilidade transformadora" (Carvalho, 2012, p. 14) amplia o escopo da Psicologia Comunitária para contribuir com norteamentos teóricos e técnicos para atuações em cotidianos marcados por diferentes identidades, condições de existência, sentidos, referências e disputas, advindas da convivência de povos rurais, de novos atores e grupos sociais inseridos nesse campo e das novas dinâmicas de reprodução das famílias.

O trabalho de psicólogas/os em contextos rurais na perspectiva da Psicologia Comunitária, já referido por Albuquerque (2002) seria, portanto, 
apreender linguagens, representações, relações grupais, emoções, afetos e formas de organização social, o que inclui o sentido e o sentimento de comunidade, de pertença, de lutas e resistências que historicamente caracterizam esse campo (Lane, 2015). Além disso, é fundamental considerar:

Primeiro, um respeito muito grande pelo "saber" dos outros. Isso exige que eu comece por prestar atenção não apenas ao que as pessoas dizem, mas também ao que as pessoas fazem. E só podemos chegar a isso na medida em que nos formos inserindo nas comunidades, com cuidado e humildade, como alguém que pede licença para poder participar. Segundo, que o projeto inclua, além do diálogo e a partilha de saberes, a garantia da autonomia e autogestão das próprias comunidades. Afinal, são eles que lá vivem, e que vão continuar a viver (Guareschi, 2015, p. 81).

Corroborando com esses argumentos, Freitas (1998) caracteriza os trabalhos desenvolvidos em comunidade, a partir de um olhar voltado para a mudança social, por meio da leitura de fenômenos psicossociais que estão presentes na vida das pessoas. As práticas teriam assim como características: serem um trabalho coletivo e orientado pelas necessidades e demandas das populações; enfrentamento de dificuldades relacionadas à espontaneidade, variação, hierarquias, retrocessos e distorções comunicacionais dos grupos; conhecimento ininterrupto sobre o cotidiano comunitário; aceitação da possibilidade de mudança; inclusão de questionamentos acerca da direção do trabalho e da própria identidade profissional; não possuir um tempo previsto para a finalização da intervenção, a depender da avaliação da comunidade.

Por outro lado, para Guzzo (2016), a presença da Psicologia Comunitária nos cursos de Psicologia aparece como uma posição burocrática, de forma que "poucas instituições de ensino assumem como um espaço importante para a formação de um outro tipo de profissional com responsabilidades, competências e habilidades diferenciadas" (p. 148). Sendo que a autora ainda acrescenta: "precisamos responder a quem a Psicologia está servindo de fato; precisamos conhecer a realidade e o cotidiano das comunidades onde as pessoas vivem" ( $p$. 150).

Ademais, em um balanço do estado atual da Psicologia Social, no plano nacional e internacional, Ferreira (2010) constatou que a maioria dos artigos de cunho teórico, sobretudo, no âmbito da Psicologia Social Crítica, tem se limitado a reflexões e defesa de determinados argumentos a partir de autores já consagrados nesse campo. Encontrou poucos trabalhos voltados para "a formulação de conceitos, metodologias ou modelos teóricos inovadores, capazes assim de colocar a Psicologia Social Crítica brasileira em posição de destaque no cenário latino-americano ou mesmo norteamericano ou europeu" (Ferreira, 2010, p.62).

Essas constatações são preocupantes, na medida em que rural é um campo que tem requisitado a construção de novos argumentos e inovações de saberes, metodologias e práticas. Caberia, pois, à formação constituir-se como 
espaço promotor de experiências e questionamentos acerca das direções e compromissos da Psicologia Comunitária, especialmente considerando as suas distâncias e insuficiências em relação à rural.

Para Ximenes, Nepomuceno e Cidade (2016), ao refletirem sobre a relação pobreza e Psicologia Comunitária, tais autores ajudam a pensar a relação entre rural e Psicologia Comunitária. Desse modo, consideram que se deve partir do contexto dos sujeitos e de seus saberes sobre sua realidade, de tal forma que a teoria existe "porque há uma realidade vivida, experienciada e capaz de ser continuamente ressignificada" (p. 180-181) e, assim, a pobreza torna-se "para a Psicologia Comunitária, não apenas cenário de atuação, mas também campo epistemológico e ontológico sobre a qual estrutura seu saber" (p. 180-181). Por isso que se justifica que é insuficiente pensar em rural apenas como um local físico de atuação.

Partindo dessas formulações entende-se 0 quanto as bases epistemológicas, teóricas e práticas que orientam a Psicologia Social Crítica/ Psicologia Comunitária precisam ser conhecidas, debatidas e aprimoradas, pois podem favorecer a construção de um lugar de permanente diálogo e de construção a respeito da produção do conhecimento e de ações interventivas em Psicologia (Lima, Ciampa, \& Almeida, 2009).

O esforço depreendido até aqui, longe de montar um panorama geral, foi o de pensar possíveis conexões e contribuições da Psicologia Social e Psicologia Comunitária para o estudo e prática em contextos rurais, sem esquecer que essas Psicologias constituem formas "mais recentes" de profissionalidade, pelo menos desde os meados dos anos 1980, porém, não foram reconhecidas nas linhas hegemônicas de formação e identidade profissional (Vasconcelos, 2011). Nesse sentido, que diálogos são possíveis e desejáveis entre Psicologia e o campo das ruralidades? Estamos dispostos a construir novos saberes em Psicologia Social e Psicologia Comunitária voltados para as relações rural/urbano? Que aprofundamentos seriam necessários nas dimensões teóricometodológicas, técnico-práticas e ético-políticas do nosso fazer profissional? Como o debate sobre rural poderia ser incorporado nos processos formativos dos cursos de graduação em Psicologia: disciplinas, estágios, ações de pesquisa e extensão universitária?

Diante dessas questões, cabe a necessidade de discutir as bases epistemológicas, teóricas, técnicas e ideo-políticas subjacentes às práticas da Psicologia em contextos rurais. Trata-se de um grande desafio na medida em que tais contextos são marcados pelas relações rural/urbano que estão em constante movimento e construção e contam com a articulação de diferentes atores e suas diferentes maneiras de dar sentido ao mundo e de viver coletivamente. Portanto, assumir o compromisso de compreender a magnitude das questões abordadas ao planejar, gerir e avaliar ações em contextos rurais torna-se uma tarefa urgente para a Psicologia. 


\section{CONSIDERAÇÕES FINAIS}

O caminho a percorrer no campo das ruralidades é longo, avaliando os 57 anos da profissão de Psicóloga/o no Brasil e os rumos que seguiram as outras diferentes áreas da Psicologia. A escassez de referências específicas e norteadores teóricos e práticos da Psicologia no campo das ruralidades indicam que ainda há muito em que avançar possivelmente pela aproximação recente da Psicologia com o estudo dessa temática e pela própria constituição da Psicologia como Ciência e Profissão, pautada em referenciais urbanos. A própria escassez de literatura para tratar sobre esse tema torna o debate sobre Psicologia e ruralidades ainda mais atual.

Como foi possível identificar, há uma ausência de clareza quanto ao lugar ocupado pela Psicologia nos contextos rurais. Tal realidade está associada à direção da formação em Psicologia, que se mantem voltada para a realidade dos grandes centros urbanos e capitais, de tal modo que as/os psicólogas/os não contam ainda com norteadores que as/os auxilie no desenvolvimento de suas capacidades teóricas, técnicas e ético-políticas para entenderem e interferirem junto aos povos e meios rurais.

Por outro lado, existe um movimento de aproximação da Psicologia com rural que precisa ser situado e compreendido de maneira mais sistemática no sentido de ajudar na construção da formação profissional para esse campo. Trata-se das contribuições da Psicologia Social, Psicologia Social Crítica/ Psicologia Comunitária, especialmente com a noção de território, que vêm se colocando como campos promissores de pesquisas e intervenções nessa área. Porém é preciso que tais campos da Psicologia produzem um diálogo mais profícuo com o chamado campo dos estudos rurais no Brasil, contribuindo e ampliando suas bases conceituais no diálogo com outras áreas com maior trajetória nesse debate: sociologia, antropologia, agronomia, geografia e economia.

Foi possível verificar ainda que a redefinição da formação profissional para atuar nesse campo passa não apenas pela redefinição dos currículos, mas inclui o avanço de outros fatores, como a participação da Psicologia no contexto universitário geral, o aumento da produção teórica, as alternativas de capacitação continuada, o avanço do movimento estudantil, e a participação das entidades representativas da categoria voltadas para esse tema, não esquecendo a aproximação com os movimentos sociais do campo.

A qualificação para atuação de psicólogas/os em contextos rurais não envolve, nesse sentido, tanto o campo do conhecimento profissional e da qualificação técnica, quanto o do compromisso ético-político. Diante disso, cabe à Psicologia se aliar às demais disciplinas e movimentos sociais na luta pela terra e demais direitos, a fim de contribuir para a construção de uma posição crítica frente aos contextos rurais, no objetivo de identificar, intervir e avaliar processos 
subjetivos, sociais, políticos, culturais, educativos e territoriais-comunitários resultantes das relações rural-urbanas.

\section{DECLARAÇÃO DE CONFLITO DE INTERESSES}

Não há conflito de interesses.

\section{REFERÊNCIAS}

Abramovay, R. (2000). Funções e medidas da ruralidade no desenvolvimento contemporâneo. Rio de Janeiro, RJ: Instituto de Pesquisa Econômica e Aplicada (IPEA).

Albuquerque, F. J. B. (2001). Aproximación metodológica desde la psicología social a la investigación en zonas rurales. Estudios Agrosociales y Pesqueros, (191), 225-233.

Albuquerque, F. J. B. (2002). Psicologia social e formas de vida rural no Brasil. Psicologia: Teoria e Pesquisa, 18(1), 037-042. doi:10.1590/S0102$3772200200010000510.1590 / S 0102-37722002000100005$

Almeida, M. W. (2007). Narrativas agrárias e morte do campesinato. RURIS, $1(2), 157-188$.

Bernardes, J. S. (2012). A formação em psicologia após 50 anos do primeiro currículo nacional da psicologia - alguns desafios atuais. Psicologia: Ciência e Profissão, 32(num. esp.), 216-231. doi:10.1590/S141498932012000500016

Blume, R. (2004). Território e ruralidade: A desmistificação do fim do rural. (Dissertação de Mestrado). Universidade Federal do Rio Grande do Sul, Porto Alegre, RS.

Brumer, A., \& Santos, J. V. T. (2006). Estudos agrários no Brasil: Modernização, violência e lutas sociais (desenvolvimento e limites da Sociologia Rural no final do século XX). Revista Nera, (9), 49-72.

Calegare, M. G. A. (2015). Rural-urbano, estudos rurais e ruralidades: Saberes necessários à Psicologia Social. In A. F. Lima, D. C. Antunes, \& M. G. A. Calegare (Eds.), A Psicologia Social e os atuais desafios ético-políticos no Brasil, (pp. 437-457). Porto Alegre, RS: ABRAPSO.

Camargo, R. A. L., \& Oliveira, J. T. A. (2012). Agricultura familiar, multifuncionalidade da agricultura e ruralidade: Interfaces de uma realidade complexa. Ciência Rural, 42(9), 1707-1714. doi:10.1590/S010384782012005000068

Campos, R. H. F. (2015). Introdução: A Psicologia Social Comunitária. In R. H. F. Campos (Ed.), Psicologia Social Comunitária: Da solidariedade à autonomia (pp. 09-14). Petrópolis, RJ: Vozes. 
Candiotto, L. Z. P., \& Corrêa, W. K. (2008). Ruralidades, urbanidades e a tecnicização do rural no contexto do debate cidade-campo. Campoterritório: Revista de geografia agrária, 3(5), 214-242.

Cardoso, P. F. (2013). Ética e projetos profissionais: Os diferentes caminhos do serviço social no Brasil. Campinas, SP: Papel Social.

Carneiro, M. J. (1998). Ruralidade: Novas identidades em construção. Estudos Sociedade e Agricultura, (11), 53-75.

Carneiro, M. J. (2005). Apresentação. In R. J. Moreira (Ed.), Identidades sociais: Ruralidades no Brasil contemporâneo (pp. 07-13). Rio de Janeiro, RJ: DP\&A. Carneiro, M. J. (2008). "Rural" como categoria de pensamento. Rurais, 2(1), 0938.

Carneiro, M. J. (2012). Do "rural" como categoria de pensamento e como categoria analítica. In M. L. Carneiro (Ed.), Ruralidades contemporâneas: Modos de viver e pensar o rural na sociedade brasileira (pp. 23-66). Rio de Janeiro, RJ: Mauad X.

Carneiro, M. J., \& Teixeira, V. L. (2012). Da terra de plantação à terra de lazer. In M. J. Carneiro (Ed.), Ruralidades Contemporâneas: Modos de viver e pensar o rural na sociedade brasileira (pp. 67-100). Rio de Janeiro, RJ: Mauad X.

Cavalcanti, J. S. B. (2004). "Globalização e ruralidade". In M. N. B. Wanderley (Ed.), Globalização e desenvolvimento sustentável: Dinâmicas rurais no Nordeste (pp. 17-32). São Paulo, SP: Polis.

Centro de Referência Técnica em Psicologia e Políticas Públicas. (2013). Referências Técnicas para Atuação das(os) Psicólogas(os) em Questões Relativas a Terra. Brasília, DF: Conselho Federal de Psicologia.

Ceolin, G. F. (2014). Crise do capital, precarização do trabalho e impactos no Serviço Social. Serviço Social \& Sociedade, (118), 239-264. doi: $10.1590 /$ S0101-66282014000200003

Coelho, M. (2013). Imediaticidade na prática profissional do Assistente Social. Rio de Janeiro, RJ: Lumen Juris.

Conti, S. Territorio y Psicología Social y Comunitaria, trayectorias/implicaciones políticas y epistemológicas. Psicologia \& Sociedade, 28(3), 484-493.

Costa, J. P., Costa, A. L. F., Lima, F. C., Seixas, P. S., Pessanha, V. C., \& Yamamoto, O. H. (2012). A produção científica sobre a formação de psicólogos no Brasil. Psicologia em Pesquisa, 6(02), 130-138. doi: $10.5327 /$ Z1982-12472012000200006

Dimenstein, M., Leite, J., Macedo, J. P., \& Dantas, C. (2017). Condições de vida e saúde mental em contextos rurais. Serviço Social \& Saúde, 16(1), 151158. doi: 10.20396/sss.v16i1.8651478

Dimenstein, M., Siqueira, K., Macedo, J. P., Leite, J., \& Dantas, C. (2017). Determinação social da saúde mental: Contribuições à psicologia no cuidado territorial. Arquivos Brasileiros de Psicologia, 69(2), 72-87. 
Do Carmo, R. M. (2009). A construção sociológica do espaço rural: Da oposição à apropriação. Sociologias, (21), 252-280.

Domingues, E. (2007). Vinte anos do MST: A psicologia nesta história. Psicologia em Estudo, 12(3), 573-582.

Favareto, A. S. (2006). Paradigmas do desenvolvimento rural em questão: Do agrário ao territorial. (Tese de Doutorado). Universidade de São Paulo, São Paulo, SP.

Favareto, A., Kleeb, S., Galvanese, C., Magalhães, C., Moralez, R., Seifer, P., ... Cardoso, R. (2015). Territórios importam: Bases conceituais para uma abordagem relacional do desenvolvimento das regiões rurais ou interioranas no Brasil. Revista em Gestão, Inovação e Sustentabilidade, 1(1), 14-46.

Fernandes, B. M., Welch, C. A., \& Gonçalves, E. C. (2013). Políticas fundiárias no Brasil: Uma análise geo-histórica da governança da terra no Brasil. In B. M. Fernandes (Ed.), Construindo um estilo de pensamento na questão agrária: O debate paradigmático e o conhecimento geográfico (pp. 67-151). Presidente Prudente, SP: Universidade Estadual Paulista.

Ferreira, M. C. (2010). A psicologia social contemporânea: Principais tendências e perspectivas nacionais e internacionais. Psicologia: Teoria e Pesquisa, 26(n. especial), 51-64.

Freitas, M. F. Q. (1998). Inserção na comunidade e análise de necessidades: Reflexões sobre a prática do psicólogo. Psicologia: Reflexão e Crítica, 11(1), 175-189. doi:10.1590/S0102-79721998000100011

Froehlich, J. M. (2012). Identidades e tradições reinventadas: O rural como tema e cenário. In M. J. Carneiro (Ed.), Ruralidades contemporâneas: Modos de viver e pensar o rural na sociedade brasileira (pp. 201-226). Rio de Janeiro, $\mathrm{RJ}$ : Mauad X.

Furtado, O. (2000). Psicologia e compromisso social: Base epistemológica de uma psicologia crítica. Revista Psicologia Social e Institucional, 2(2), 217229.

Guareschi, P. (2015). Relações comunitárias: Relações de dominação. In R. H. F. Campos (Ed.), Psicologia Social Comunitária: Da solidariedade à autonomia (pp. 66-81). Petrópolis, RJ: Vozes.

Guzzo, R. S. L. Apresentação (2015). In A. Accorssi, A. B. S. Bousfiel, H. S. Gonçalves, K. Aguiar, \& R. S. L. Guzzo (Ed.), Distintas faces da questão social: Desafios para a Psicologia, (pp. 03-07). Florianópolis, SC: ABRAPSO.

Guzzo, R. S. L. (2016). A quem a Psicologia serve? Sobre a importância da Psicologia Comunitária. In V. M. Ximenes, J. C. Sarriera, Z. A. C. Bonfim, \& J. A. I. (Ed.), Psicologia Comunitária no mundo atual: Desafios, limites e fazeres, (pp. 139-152). Fortaleza, CE: Expressão Gráfica e Editora.

Iamamoto, M. V. (2008). O Serviço Social na contemporaneidade: Trabalho e formação profissional. São Paulo, SP: Cortez. 
Kayser, B. (1990). La renaissancerurale. Sociologie des campagnes du monde occidental. Paris, FR: Armand Colin.

Landini, F. (2015). La noción de psicología rural y susdesafíosenel contexto latinoamericano. In F. Landini (Ed.), Hacia una psicología rural latinoamericana. Ciudad Autónoma de Buenos Aires: CLACSO.

Lane, S. T. M. (2007). Histórico e fundamentos da Psicologia Comunitária no Brasil. In R. H. F. Campos (Ed.), Psicologia Social Comunitária (pp. 54-80). Petrópolis, RJ: Vozes.

Lane, S. T. M. (2015). Histórico e fundamentos da Psicologia Comunitária no Brasil. In R. H. F. Campos (Ed.), Psicologia Social Comunitária: Da solidariedade à autonomia (pp. 15-28). Petrópolis, RJ: Vozes.

Lane, S. T. M., \& Sawaia, B. B. (1995). Novas veredas da Psicologia Social. São Paulo, SP: Brasiliense.

Leão, S. M., Oliveira, I. M. F. F., \& Carvalho, D. B. (2014). O Psicólogo no campo do bem-estar social: Atuação junto às famílias e indivíduos em situação de vulnerabilidade e risco social no Centro de Referência de Assistência Social (CRAS). Estudos e Pesquisas em Psicologia, 14(1), 264-289.

Leite, J. F., \& Dimenstein, M. (2006). Subjetividade em movimento: O MST no Rio Grande do Norte. Psicologia \& Sociedade, 18(1), 21-30. doi:10.1590/S0102-71822006000100004.

Leite, J. F., \& Dimenstein, M. (2010). Movimentos sociais e produção de subjetividade: O MST em perspectiva. Psicologia \& Sociedade, 22(2), 269278. doi: $10.1590 / S 0102-71822010000200007$

Leite, J. F., Macedo, J. P. S., Dimenstein, M., \& Dantas, C. (2013). A formação em Psicologia para a atuação em contextos rurais. In J. F. Leite, \& M. Dimenstein (Eds.), Psicologia e contextos rurais (pp. 27-55). Natal, RN: EDUFRN.

Lemos, F. C. S., \& Galindo, D. C. G. (2013). Massacre e Resistência Kaiowá e Guarani: Interrogações às Psicologias nos Traçados do Intolerável. Psicologia: Ciência e Profissão, 33(4), 976-987. doi:10.1590/S141498932013000400015

Lima, A. F., Ciampa, A. C., \& Almeida, J. A. M. (2009). Psicologia Social como psicologia política? A proposta de Psicologia Social Crítica de Sílvia Lane. Psicologia Política, 9(18), 223-236.

Lindner, M., Alves, F. D., \& Ferreira, E. R. (2009). Presença da ruralidade em municípios gaúchos: O exemplo de Silveira Martins, RS. In XIX Encontro Nacional de Geografia Agrária (pp. 01-15). São Paulo, SP.

Little, P. E. (2002). Territórios sociais e povos tradicionais no Brasil: Por uma antropologia da territorialidade. Série Antropologia no 322. Brasília, DF: Universidade de Brasília.

Lopes, J. R. (2007). A questão social da terra como desafio para a psicologia. Psicologia em Estudo, 12(3), 583-592. 
Martins, A. M. (2010). A formação em psicologia e a percepção do meio rural: Um debate necessário. Psicologia: Ensino \& Formação, 1(1), 83-98.

Martins, S. T. F. (2007). Psicologia social e processo grupal: A coerência entre fazer, pensar e sentir em Sílvia Lane. Psicologia \& Sociedade, 19, 76-80. doi: $10.1590 /$ S0102-71822007000500022

Matos, E. A. C., \& Medeiros, R.M.V. (2011). A relação campo-cidade e as "novas" ruralidades. ParaOnde!?, 5(1), 01-15.

Montaño, C., \& Duriguetto, M. L. (2010). Estado, classe e movimento social. São Paulo, SP: Cortez.

Moraes, M. D. C. (2014). Ruralidades no Brasil: Qual o lugar das políticas de cultura? Rede de estudos rurais, Campinas, SP.

Moraes, M. D. C., \& Vilela, S. L. O. (2013). Trilhas de um debate contemporâneo: Ruralidades, campesinato, novo nominalismo. Revista FSA, 10(1), 59-85.

Moreira, R. J. (2005a). Ruralidades e globalizações: Ensaiando uma interpretação. In: R. J. Moreira (Ed.), Identidades sociais: Ruralidades no Brasil contemporâneo (pp. 15-40). Rio de Janeiro, RJ: DP\&A.

Moreira, R. J. (2005b). Identidades sociais em territórios rurais fluminenses. In: R. J. Moreira (Ed.), Identidades sociais: Ruralidades no Brasil contemporâneo (pp. 65-88). Rio de Janeiro, RJ: DP\&A.

Moreira, R. J. (2009). Terra, poder e território. São Paulo, SP: Expressão Popular.

Netto, J. (2001). Cinco notas a propósito da questão social. Revista Temporalis, 2(3). Brasília, DF: ABEPSS.

Rechtman, R. (2015). O futuro da Psicologia brasileira: Uma questão de projeto político. Revista psicologia, diversidade e saúde, 4(1), 69-77. doi: 10.17267/2317-3394rpds.v4i1.578

Rosa, L. A., \& Silva, A. P. S. (2015). Sujeito político dramático: Mudanças vivenciadas por uma militante do MST. Psicologia \& Sociedade, 27(1), 4757. doi: 10.1590/1807-03102015v27n1p047

Sawaia, B. B. (1995). Psicologia Social: Aspectos epistemológicos e éticos. In B. B. Sawaia, \& S. T. M. Lane (Eds.), Novas veredas da Psicologia Social (pp. 45-53). São Paulo, SP: Brasiliense.

Sawaia, B. B. (2007). Comunidade: A apropriação cientifica de um conceito tão antigo quanto a humanidade. In R. H. F. Campos (Ed.), Psicologia Social comunitária (pp. 54-80). Petrópolis, RJ: Vozes.

Scarparo, H. B. K., \& Guareschi, N. M. F. (2007). Psicologia social comunitária e formação profissional. Psicologia \& Sociedade, 19(Edição Especial 2), 100108. doi:10.1590/S0102-71822007000500025

Schneider, S. (1997). Da crise da sociologia rural à emergência da sociologia da agricultura: Reflexões a partir da experiência norte-americana. Cadernos de Ciência \& Tecnologia, 14(2), 225-256. 
Silva, C. A., \& Rocha, F. G. (2011). Contribuições da sociología rural norteamericana e europeia aos conceitos de rural, urbano e suas relações. Cuadernos de Geografía, Revista Colombiana de Geografía, 20(2), 09-19.

Silva, J. G. (1980). O que é questão agrária. São Paulo, SP: Brasiliense.

Silva, J. G. (1982). A modernização dolorosa: Estrutura agrária, fronteira agrícola e trabalhadores rurais no Brasil. Rio de Janeiro, RJ: Zahar Editores.

Silva, J. G. (1996). A nova dinâmica da agricultura brasileira. Campinas, SP: Universidade Estadual de Campinas.

Silva, J. G. (2001). Velhos e novos mitos do rural brasileiro. Estudos avançados, 15(43), 37-50. doi:10.1590/S0103-40142001000300005

Vasconcelos, E. M. (2011). Os psicólogos e sua inserção no SUAS: Da sensação inicial de perda de identidade ao reconhecimento de uma nova profissionalidade e de suas bases teóricas. In R. Morgado, E. M. Vasconcelos, \& J. Garcia (Eds.), Cadernos de Assistência Social, volume 1: contribuições para a proteção básica e proteção especial. Resende, RJ: Secretaria Municipal de Assistência Social e Direitos Humanos.

Vasquez, G. C. F. (2009). A Psicologia na área rural: Os assentamentos da reforma agrária e as mulheres assentadas. Psicologia Ciência e Profissão, 29(4), 856-867.

Veiga, J. E. (2001). O Brasil rural ainda não encontrou seu eixo de desenvolvimento. Estudos Avançados, 15(43), 101-119.

Wanderley, M. N. B. (2000). A emergência de uma nova ruralidade nas sociedades modernas avançadas: O "rural" como espaço singular e ator coletivo. Estudos Sociedade e Agricultura, (15), 87-145.

Wanderley, M. N. B. (2001). A ruralidade no Brasil moderno. Por um pacto social pelo desenvolvimento rural. In N. Giarracca (Ed.), Una nueva ruralidad en America Latina? (pp. 31-44). Buenos Aires, AR: Clocso.

Wanderley, M. N. B. (2011). Um saber necessário: Os estudos rurais no Brasil. Campinas, SP: Editora da Unicamp.

Wanderley, M. N. B. (2012). Prefácio. In M. J. Carneiro (Ed.), Ruralidades Contemporâneas: Modos de viver e pensar o rural na sociedade brasileira (pp. 15-17). Rio de Janeiro, RJ: Mauad X.

Williams, R. (2011). O campo e a cidade. Na história e na literatura. São Paulo, SP: Companhia das Letras.

Ximenes, V. M., Nepomuceno, B.B., \& Cidade, E.C. (2016). Pobreza: Um problema para a Psicologia Comunitária? In V. M. Ximenes, J. C. Sarriera, Z. A. C. Bonfim, \& J. A. I. (Eds.), Psicologia Comunitária no mundo atual: Desafios, limites e fazeres, (pp. 175-195). Fortaleza, CE: Expressão Gráfica e Editora. 
Sobre os autores

Kátya de Brito e Silva é psicóloga pela Universidade Federal do Piauí, mestre em Políticas Públicas e doutoranda em Psicologia pela Universidade Federal do Rio Grande do Norte. katyabrito.s@gmail.com.

João Paulo Macedo é psicólogo pela Faculdade Santo Agostinho, mestre e doutor em Psicologia pela Universidade Federal do Rio Grande do Norte. Atua como Docente do Programa de Pós-Graduação em Psicologia da Universidade Federal do Piauí, na linha Psicologia, Saúde Coletiva e Processos de Subjetivação, é bolsista de produtividade do CNPQ.jpmacedo@ufpi.edu.br.

A contribuição de cada autor pode ser atribuída como se segue: K.B.S e J.P.M. participaram ativamente de todo o processo de concepção, desenvolvimento e escrita do manuscrito.

Os autores agradecem a Coordenação de Aperfeiçoamento de Pessoal de Nível Superior pelo financiamento da bolsa de mestrado da primeira autora

Recebido em: 23/10/2017

$1^{a}$ revisão em: $15 / 03 / 2018$

Aceito em: 02/06/2018 